\title{
Diagnostic Dilemma of Aspergillus Meningitis in Patients With Hepatitis C Virus Co-Infection: A Case Series
}

\author{
Joseph Seemiller ${ }^{\mathrm{a}, \mathrm{b}}$, Muhammad Taimur Malik ${ }^{\mathrm{a}, \mathrm{b}, \mathrm{c}}$
}

\begin{abstract}
Aspergillus meningitis can occur in immunocompromised and immunocompetent patients. The diagnostic yield is only $39 \%$ in immunocompromised patients and $69 \%$ in immunocompetent patients. Diagnosis can be challenging, as repeated cerebrospinal fluid (CSF) cultures can be negative. Even with multiple cultures, the diagnostic yield is meager, sometimes requiring a tissue diagnosis. However, prompt recognition and treatment initiation are crucial to minimize morbidity. We present two cases of patients with a history of intravenous drug use disorder (IVDU) co-infected with hepatitis $\mathrm{C}$ virus (HCV) and Aspergillus. Two young Caucasian patients with untreated HCV infection and a history of IVDU, presented with fevers and headaches. Their imaging and multiple CSF samples showing pleocytosis with negative fungal cultures led to a diagnostic dilemma. Due to progressive decline and to ascertain a definitive diagnosis, a brain biopsy resulted in a tissue diagnosis of fungal meningitis secondary to Aspergillus, with hyphae and granulomas, in both individuals. In the workup of chronic meningitis, Aspergillus infection should be strongly considered in patients with IVDU and HCV co-infection. In patients with chronic meningitis lacking definitive diagnosis from spinal fluid, tissue sampling should be pursued as soon as possible to ensure rapid treatment and prevent disability. $\mathrm{HCV}$ is associated with a reduction in cellular immunity; our two cases support that $\mathrm{HCV}$ and a history of IVDU carry risks of immunosuppression, warranting early and expedited workup for chronic fungal meningitis.
\end{abstract}

Keywords: Aspergillus infection; $\mathrm{HCV}$ infection; Chronic meningitis

\section{Introduction}

Life-threatening infections from Aspergillus are most com-

Manuscript submitted August 17, 2021, accepted December 28, 2021

Published online February 28, 2022

${ }^{\mathrm{a}}$ Geisinger Commonwealth School of Medicine, Scranton, PA, USA bDepartment of Neurology, Geisinger Neuroscience Institute, Danville, PA 17822, USA

'Corresponding Author: Muhammad Taimur Malik, Department of Neurology, Geisinger Neuroscience Institute, Danville, PA 17822, USA.

Email:mmalik@geisinger.edu

doi: https://doi.org/10.14740/jnr706 mon in patients lacking cellular immunity. However, other predisposing factors, including intravenous drug use disorder (IVDU) and hepatitis $\mathrm{C}$ virus (HCV) infection, can increase susceptibility to cerebral aspergillosis. With the mortality rate of Aspergillus infection estimated to be $45 \%$ overall [1] and as high as $72 \%$ in immunocompromised patients [2], early identification and treatment is essential to prevent increased morbidity and mortality. Indeterminate cerebrospinal fluid (CSF) studies and poorly elucidated radiographic features of central nervous system (CNS) in Aspergillus infection are the reasons why tissue biopsy is often required to finalize a diagnosis and should not be delayed, especially when a target amendable to biopsy is identified on CNS imaging.

\section{Case Reports}

\section{Case 1}

A 38-year-old Caucasian male with history of IVDU and chronic untreated HCV infection presented with new-onset generalized headache, intermittent diplopia, and recurrent fevers. On presentation, 1 month after onset of headaches, he had no focal neurologic deficits, but did have multiple psoriatic plaques across his face and elbows. Computed tomography (CT) head showed communicating hydrocephalus, and magnetic resonance imaging (MRI) brain showed a rim-enhancing lesion in the suprasellar cistern with diffusion restriction (Fig. 1). CSF showed 128 white blood cells (WBCs), protein 167 $\mathrm{mg} / \mathrm{dL}$, and opening pressure of $31 \mathrm{~mm}_{2} \mathrm{O}$. Broad-spectrum antibiotics including ceftriaxone $2 \mathrm{~g}$ intravenous (IV) every 12 $\mathrm{h}$, vancomycin $15 \mathrm{mg}$ every $12 \mathrm{~h}$ and acyclovir $10 \mathrm{mg} / \mathrm{kg}$ IV every $8 \mathrm{~h}$ (until polymerase chain reaction (PCR) was negative) were continued. The patient's workup was limited by multiple hospital elopements. CSF obtained 1 month later showed $8 \mathrm{WBCs} / \mathrm{mm}^{3}$ and $167 \mathrm{mg} / \mathrm{dL}$ protein with opening pressure $44 \mathrm{~mm} \mathrm{H} \mathrm{H}_{2} \mathrm{O}$. CSF 2 months later showed $50 \mathrm{WBCs} / \mathrm{mm}^{3}$ and $105 \mathrm{mg} / \mathrm{dL}$ protein with opening pressure $39 \mathrm{~mm} \mathrm{H}_{2} \mathrm{O}$. CSF 3 months later showed $11 \mathrm{WBCs} / \mathrm{mm}^{3}$ and $131 \mathrm{mg} / \mathrm{dL}$ protein with opening pressure of $36 \mathrm{~mm} \mathrm{H}_{2} \mathrm{O}$. Aerobic, anaerobic, and fungal CSF cultures were collected with each lumbar puncture and were negative. Patient was later discharged to inpatient rehab and subsequently went home.

Thirteen months after initial presentation, he developed left-sided weakness with $4 / 5$ strength in the left upper extremity (LUE) and 4-/5 in the left lower extremity. Spinal 


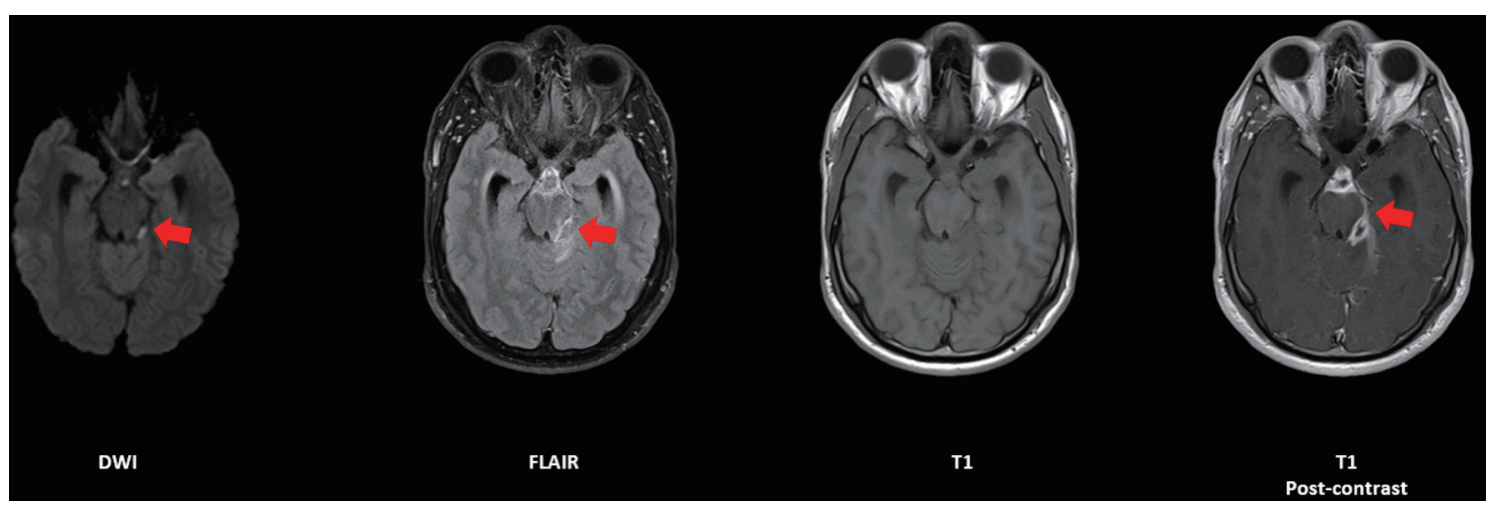

Figure 1. Axial sequences of an MRI brain with and without contrast, demonstrating a rim-enhancing lesion in the suprasellar cistern with restricted diffusion, indicated by red arrows (case 1). MRI: magnetic resonance imaging.

MRI was remarkable for multiple mass-like intrathecal extramedullary enhancing lesions associated with a subarachnoid and dural enhancement in the cervical and thoracic spine. Repeat lumbar puncture showed $256 \mathrm{WBCs} / \mathrm{mm}^{3},>$ $600 \mathrm{mg} / \mathrm{dL}$ protein, 2,000 red blood cells $(\mathrm{RBCs}) / \mathrm{mm}^{3}$, and opening pressure of $23 \mathrm{~mm} \mathrm{H}_{2} \mathrm{O}$. As the cause of his chronic meningitis remained cryptogenic despite six CSF samples and a total of seven negative aerobic, anaerobic, and fungal CSF cultures, and an enhancing pathologic target was finally found in the spine, a dorsal cervical medullary biopsy was completed showing granulation tissue and abscess with many fungal organisms.

Voriconazole $200 \mathrm{mg}$ twice daily was initiated. However, 2 months later, he presented with episodes of respiratory arrest and shaking in bilateral upper and lower extremities without electroencephalogram (EEG) correlate. These muscle spasms were likely related to the worsening hydrocephalus as evident from the CT head showing enlargement of the prepontine and infrapontine cisterns as well as the fourth ventricle causing pontine compression. CSF studies showed $7 \mathrm{WBCs} / \mathrm{mm}^{3}$ with $9,000 \mathrm{RBCs} / \mathrm{mm}^{3}$ and $43 \mathrm{mg} / \mathrm{dL}$ protein, which was thought reflective of proper treatment of his chronic meningitis, despite his new symptoms. An external ventricular drain (EVD) was placed; however, there was no clinical improvement and he continued to have episodic respiratory arrest and diffuse full body shaking. Soon thereafter, the patient's family selected to pursue comfort care and the patient passed away.

\section{Case 2}

A 31-year-old Caucasian male with history of chronic HCV infection and IV drug use (in remission for 3 years) presented with a 6-month history of daily posterior headaches with no focal neurological deficits at presentation. CT head showed communicating hydrocephalus, and brain MRI showed basilar enhancement. Spinal MRI showed cervical and thoracic cord T2 hyperintensity extending from the medulla to about the T3 cord level (Fig. 2). CSF showed $470 \mathrm{WBCs} / \mathrm{mm}^{3}$ with lymphocytic predominance, $>600 \mathrm{mg} / \mathrm{dL}$ protein, and with negative bacterial cultures and negative fungal smear and culture. Serum studies including human immunodeficiency virus (HIV), rapid plasma reagin (RPR), QuantiFERON, Lyme, and angiotensin-converting enzyme (ACE) were negative. He was treated empirically for bacterial meningitis, yet MRI brain continued to show evidence of leptomeningeal enhancement with cervicothoracic T2 hyperintensity (Fig. 2a). The patient's headache symptoms improved following EVD placement and steroids. Repeat lumbar puncture 2 weeks after initial presentation showed $2 \mathrm{WBCs} / \mathrm{mm}^{3}, 7 \mathrm{mg} / \mathrm{dL}$ protein, and negative fungal culture. He had a worsening headache, bilateral upper

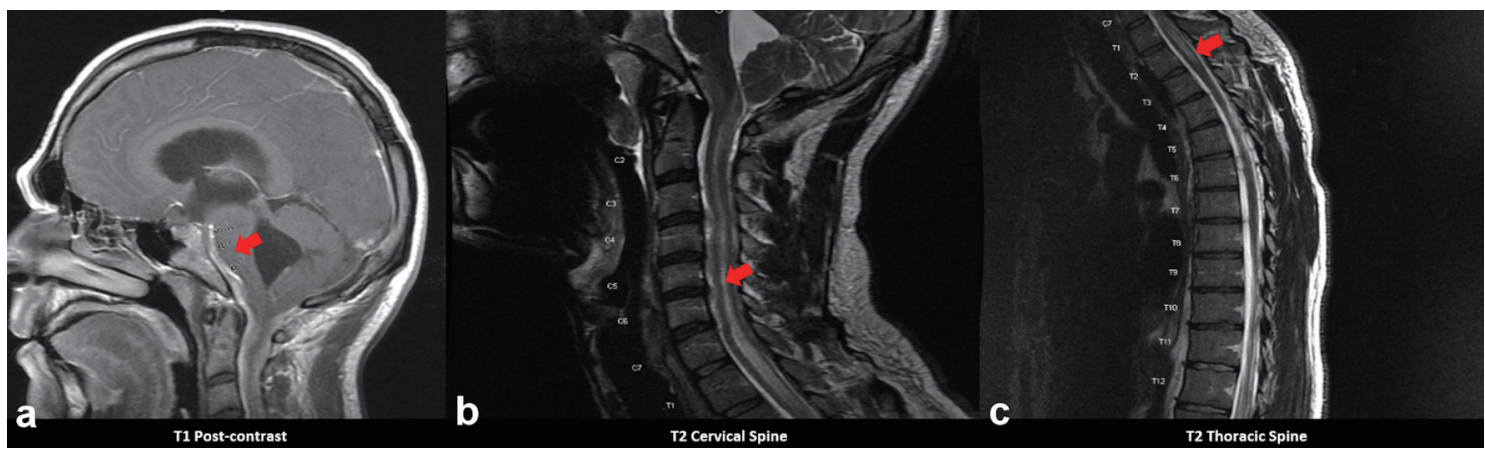

Figure 2. MRI brain with and without contrast showing (a) leptomeningeal enhancement most prominent along the ventral margin of the brainstem and perimesencephalic cisterns, indicated by the red arrow. Images (b) and (c) depict hyperintensity along the cervical and thoracic spine, indicated by red arrows (case 2). MRI: magnetic resonance imaging. 


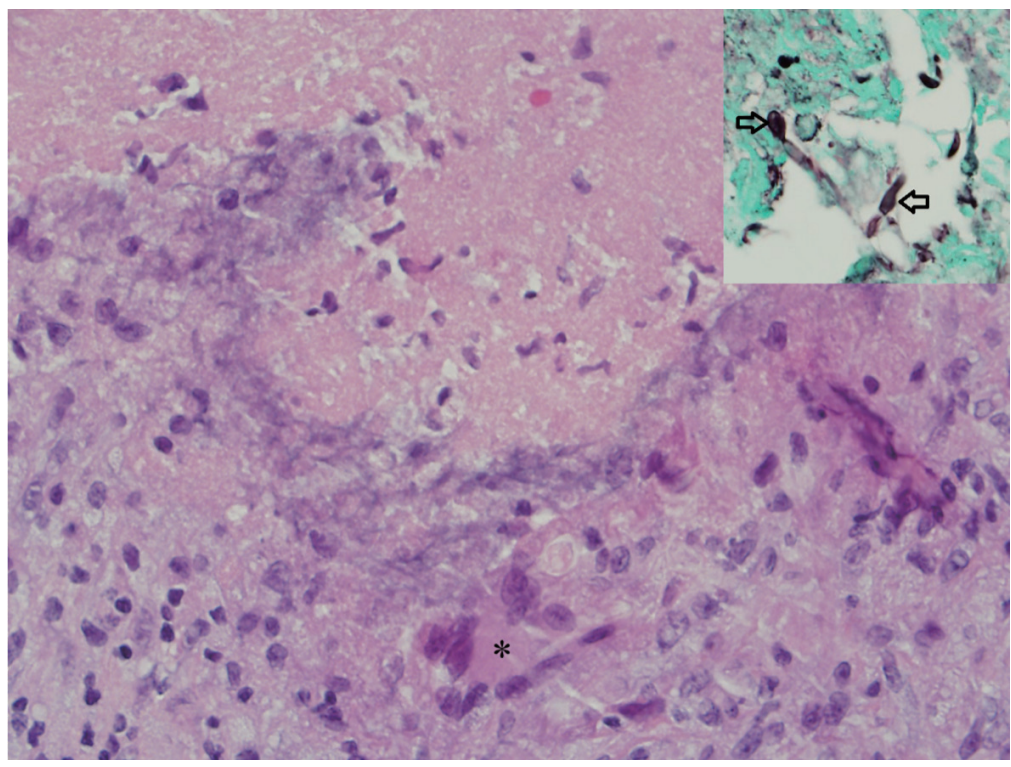

Figure 3. Hematoxylin and eosin (H\&E) stained photomicrograph showing a necrotizing granuloma with a central necrosis surrounded by lymphocytes, epithelioid histiocytes and giant cell (asterisk). Inset shows septate fungal hyphae on a GMS special stain.

extremity weakness (4-/5 in both the LUE and right upper extremity (RUE)), and episodes of loss of consciousness which was unwitnessed. MRI showed T2 hyperintensity in the central gray matter of the cervical spine, consistent with cervicothoracic syrinx causing myelopathy (Fig. 2b, c). A third lumbar puncture 1 month after initial presentation showed $35 \mathrm{WBCs} /$ $\mathrm{mm}^{3}, 32 \mathrm{mg} / \mathrm{dL}$ protein, and negative fungal culture. He had EVD placement and Chiari decompression surgery and biopsy. Tissue biopsy revealed fungal organisms with several septate fungal hyphae, consistent with Aspergillus infection (Fig. 3). The patient neurological examination was concerning for bilateral upper and lower extremity progressive weakness, decreased sensation to pin prick and ambulatory dysfunction. After his biopsy, he was started on empiric antifungal treatment which included fluconazole $800 \mathrm{mg}$ once daily oral as he was not able to tolerate the amphotericin B, prior to finalization of Aspergillus meningitis based on tissue biopsy, and he reported some improvement in his symptoms. Unfortunately, throughout his workup, lasting 2 - 3 months, he developed progressive weakness of all four extremities. After his symptoms stabilized, he remained with marked weakness and was wheelchair dependent.

\section{Discussion}

Aspergillosis is a common fungal opportunistic infection in both immunocompromised and immunocompetent patients. Although it only comprises about $5 \%$ of all CNS fungal infections, the overall prognosis is poor. Mortality rates can be $45 \%$ overall [1] and as high as $72 \%$ in immunocompromised patients [2].

With a recent increase in solid organ transplantation and new immunosuppressive agents, invasive fungal infections have increased. Usually, the transmission for Aspergillus is via respiratory route, but it can enter the CNS through the paranasal sinuses from trauma which seems to be more prevalent in immunocompetent patients. At the same time, hematogenous spread is more common in immunocompromised patients.

$\mathrm{HCV}$ has been independently associated with transverse myelitis [3], suggesting direct invasion of nervous tissue [4, 5] by $\mathrm{HCV}$ or by an immune response [6] to HCV. HCV has also been associated with other CNS disorders including vasculitis, meningoencephalitis, encephalomyelitis, and cognitive behavioral deficits [7].

Susceptibility to chronic fungal meningitis, particularly cryptococcal meningitis, has been related to T-lymphocyte deficits in HIV-infected individuals. Therefore, it may seem paradoxical that $\mathrm{HCV}$ is also a predisposing factor to chronic fungal meningitis, as HCV causes sustained over-activation of $\mathrm{CD}^{+}$T-cells in those with advanced liver disease [8, 9]. Impairment of innate host defenses [10] against Aspergillus could explain susceptibility to the disease. Specifically, natural killer cells have been found to decrease in patients with chronic HCV infection [11], and they remain an important part of innate host defenses against Aspergillus [10]. Additionally, from the idea that chronic immune system overactivation in $\mathrm{HCV}$ leads to increased vulnerability, adjunctive immunosuppression has been considered for treatment of non-HIV cryptococcal meningitis and used with favorable results in some cases $[9,12]$. Additional theories for immunocompromise in chronic HCV infection could include T-cell exhaustion due to persistent antigens to HCV [13] and dendritic cell dysfunction which impairs cytokine-dependent T-cell priming and natural killer cell maturation $[14,15]$.

In the workup of chronic meningitis, Aspergillus infection should be strongly considered in patients with IVDU and HCV co-infection. Risk factors for fungal meningitis, in the absence 
of other causes of clear compromise to cellular immunity, have been suggested to include drug addition, chronic alcoholism, hepatic failure [16, 17], as well as HCV co-infection [18, 19]. Our report supports that together, both IVDU and HCV can increase the risk for the development of fungal or Aspergillus meningitis. Many other predisposing factors, including chronic alcoholism, drug addiction, liver failure and certain occupations, are more vulnerable to Aspergillus infection [2, 20-22]. Our two cases of untreated $\mathrm{HCV}$ infection with past or ongoing IVDU illustrate the vulnerability of these populations as well.

Immunocompetent patients are known to generally be affected by a less aggressive form of neuroaspergillosis, notable for granulomas and brain abscesses [23], whereas immunocompromised patients are more frequently afflicted with angiotrophic disease [24]. Aspergillus, a branched hypha, can obstruct vascular lumens leading to vasculitis, cerebral infarction, and intraparenchymal hemorrhage due to weakening of the vascular wall [25]. Pathology can be notable for necrotizing granulomas with central necrosis surrounded by epithelioid histiocytes and giant cells (Fig. 3).

In an analysis of eight patients with pathologically confirmed CNS aspergillosis [26], focal brain lesions were most commonly found in the cerebral hemispheres, with two-thirds in the subcortical white matter. Lesions greater than $15 \mathrm{~mm}$ were associated with hemorrhage. Prior studies have shown that the ring-enhancing lesions associated with Aspergillus abscesses seem to have irregular and hypointense signals on MRI [26].

Various antifungals have been used to treat CNS aspergillosis including amphotericin B and itraconazole [27, 28]. Still, a more prolonged treatment is recommended for resolution of all the lesions and clinical symptoms, such as a longer treatment course of voriconazole together with neurosurgical management [29]. As discussed earlier, corticosteroids have been used in select cases of cryptococcal meningitis associated with HCV infection; however the use of corticosteroids has not been systematically studied in cryptococcal meningitis or other etiologies of fungal meningitis.

In the workup of chronic meningitis, multiple different CSF cultures are recommended. However, escalation of workup to include tissue biopsy should be strongly considered and not delayed in the workup of cryptogenic chronic meningitis especially with multiple negative CSF cultures. Fungal cultures can be repeatedly negative, as many as seven times for case 1 , with final diagnosis only made through a tissue biopsy. It is also essential to identify patterns placing patients at higher risk of chronic meningitis, such as co-infection with organisms like $\mathrm{HCV}$, to decrease mortality and morbidity associated with these co-infections.

\section{Acknowledgments}

None to declare.

\section{Financial Disclosure}

None to declare.

\section{Conflict of Interest}

None to declare.

\section{Informed Consent}

Informed consents were obtained.

\section{Author Contributions}

Both authors contributed to the collection of data and writing of the manuscript.

\section{Data Availability}

The data supporting the findings of this study are available from the corresponding author upon reasonable request.

\section{References}

1. Meena DS, Kumar D, Bohra GK, Kumar G. Clinical manifestations, diagnosis, and treatment outcome of CNS aspergillosis: A systematic review of 235 cases. Infect Dis Now. 2021;51(8):654-660.

2. Antinori S, Corbellino M, Meroni L, Resta F, Sollima S, Tonolini M, Tortorano AM, et al. Aspergillus meningitis: a rare clinical manifestation of central nervous system aspergillosis. Case report and review of 92 cases. J Infect. 2013;66(3):218-238.

3. Aktipi KM, Ravaglia S, Ceroni M, Nemni R, Debiaggi M, Bastianello S, Alfonsi E, et al. Severe recurrent myelitis in patients with hepatitis $\mathrm{C}$ virus infection. Neurology. 2007;68(6):468-469.

4. Seifert F, Struffert T, Hildebrandt M, Blumcke I, Bruck $\mathrm{W}$, Staykov D, Huttner HB, et al. In vivo detection of hepatitis $\mathrm{C}$ virus (HCV) RNA in the brain in a case of encephalitis: evidence for HCV neuroinvasion. Eur J Neurol. 2008;15(3):214-218.

5. Laskus T, Radkowski M, Adair DM, Wilkinson J, Scheck AC, Rakela J. Emerging evidence of hepatitis C virus neuroinvasion. AIDS. 2005;19(Suppl 3):S140-144.

6. Monaco S, Ferrari S, Gajofatto A, Zanusso G, Mariotto $\mathrm{S}$. HCV-related nervous system disorders. Clin Dev Immunol. 2012;2012:236148.

7. Umphlett M, Bryce C, Morgello S. CNS disorders caused by hepatitis $\mathrm{C}$ and hepatitis $\mathrm{E}$ viruses. In: Chretien $\mathrm{F}$, Wong KT, Sharer LR, Keohane C (Katy), Gray F, eds. Infections of the Central Nervous System. Wiley. 2020; 177-181.

8. Vranjkovic A, Deonarine F, Kaka S, Angel JB, Cooper CL, Crawley AM. Direct-Acting Antiviral Treatment of HCV Infection Does Not Resolve the Dysfunction of Circulating CD8(+) T-Cells in Advanced Liver Disease. Front Immunol. 2019;10:1926. 
9. Panackal AA, Wuest SC, Lin YC, Wu T, Zhang N, Kosa P, Komori M, et al. Paradoxical immune responses in Non-HIV cryptococcal meningitis. PLoS Pathog. 2015;11(5):e1004884.

10. Walsh TJ, Roilides E, Cortez K, Kottilil S, Bailey J, Lyman CA. Control, immunoregulation, and expression of innate pulmonary host defenses against Aspergillus fumigatus. Med Mycol. 2005;43(Suppl 1):S165-172.

11. Strunz B, Hengst J, Deterding K, Manns MP, Cornberg M, Ljunggren $\mathrm{HG}$, Wedemeyer $\mathrm{H}$, et al. Chronic hepatitis $\mathrm{C}$ virus infection irreversibly impacts human natural killer cell repertoire diversity. Nat Commun. 2018;9(1):2275.

12. Tanu S, Mihir M, Rajeev S, Annu A. Neurological worsening during treatment of an immunocompetent adult with Cryptococcus neoformans meningitis. Med Mycol Case Rep. 2020;27:48-51.

13. Wherry EJ, Ha SJ, Kaech SM, Haining WN, Sarkar S, Kalia V, Subramaniam S, et al. Molecular signature of $\mathrm{CD} 8+\mathrm{T}$ cell exhaustion during chronic viral infection. Immunity. 2007;27(4):670-684.

14. Zimmermann M, Flechsig C, La Monica N, Tripodi M, Adler G, Dikopoulos N. Hepatitis $\mathrm{C}$ virus core protein impairs in vitro priming of specific $\mathrm{T}$ cell responses by dendritic cells and hepatocytes. J Hepatol. 2008;48(1):5160.

15. Ebihara T, Shingai M, Matsumoto M, Wakita T, Seya T. Hepatitis C virus-infected hepatocytes extrinsically modulate dendritic cell maturation to activate $T$ cells and natural killer cells. Hepatology. 2008;48(1):48-58.

16. Kim DG, Hong SC, Kim HJ, Chi JG, Han MH, Choi KS, Han DH. Cerebral aspergillosis in immunologically competent patients. Surg Neurol. 1993;40(4):326-331.

17. Polk C, Meredith J, Kuprenas A, Leonard M. Cryptococcus meningitis mimicking cerebral septic emboli, a case report series demonstrating injection drug use as a risk factor for development of disseminated disease. BMC Infect Dis. 2020;20(1):381.

18. Yamahiro A, Lau KH, Peaper DR, Villanueva M. Meningitis Caused by Candida Dubliniensis in a Patient with Cirrhosis: A Case Report and Review of the Literature. Mycopathologia. 2016;181(7-8):589-593.
19. Tahir M, Peseski AM, Jordan SJ. Case Report: Candida dubliniensis as a Cause of Chronic Meningitis. Front Neurol. 2020;11:601242.

20. Benninger F, Steiner I. CSF in acute and chronic infectious diseases. Handb Clin Neurol. 2017;146:187-206.

21. Hadley C, Haneef Mohamed AW, Singhal A. Central nervous system fungal infection in a young male with a history of intravenous drug abuse and hepatitis C. Radiol Case Rep. 2017;12(3):590-596.

22. Iriana S, Curry MP, Afdhal NH. Neurologic Manifestations of Hepatitis C Virus Infection. Clin Liver Dis. 2017;21(3):535-542.

23. Bokhari R, Baeesa S, Al-Maghrabi J, Madani T. Isolated cerebral aspergillosis in immunocompetent patients. World Neurosurg. 2014;82(1-2):e325-333.

24. Guermazi A, Gluckman E, Tabti B, Miaux Y. Invasive central nervous system aspergillosis in bone marrow transplantation recipients: an overview. Eur Radiol. 2003;13(2):377-388.

25. DeLone DR, Goldstein RA, Petermann G, Salamat MS, Miles JM, Knechtle SJ, Brown WD. Disseminated aspergillosis involving the brain: distribution and imaging characteristics. AJNR Am J Neuroradiol. 1999;20(9):15971604.

26. Yamada K, Shrier DA, Rubio A, Shan Y, Zoarski GH, Yoshiura T, Iwanaga S, et al. Imaging findings in intracranial aspergillosis. Acad Radiol. 2002;9(2):163-171.

27. Bennett JE, Dismukes WE, Duma RJ, Medoff G, Sande MA, Gallis H, Leonard J, et al. A comparison of amphotericin $\mathrm{B}$ alone and combined with flucytosine in the treatment of cryptoccal meningitis. N Engl J Med. 1979;301(3):126-131.

28. de Gans J, Portegies P, Tiessens G, Eeftinck Schattenkerk JK, van Boxtel CJ, van Ketel RJ, Stam J. Itraconazole compared with amphotericin B plus flucytosine in AIDS patients with cryptococcal meningitis. AIDS. 1992;6(2):185-190.

29. Schwartz S, Ruhnke M, Ribaud P, Corey L, Driscoll $\mathrm{T}$, Cornely OA, Schuler U, et al. Improved outcome in central nervous system aspergillosis, using voriconazole treatment. Blood. 2005;106(8):2641-2645. 